\title{
El país de la canela de William Ospina, ¿Nueva novela histórica o una vuelta a la novela romántica del siglo XIX?
}

\author{
Will new historical novel or a return to the romantic novel of \\ the nineteenth century?
}

Sandra Morales Muñoz

Recibido: 1 de Marzo 2013. Aprobado: 10 de Abril de 2013.

\begin{abstract}
Resumen
El país de la canela (2008), de William Ospina (1954) merece atención, entre otras, por la materia y el tema que resalta a primera vista. Alejándose de la corriente temática narrativa de sus contemporáneos colombianos, en las puertas del siglo XXI, Ospina escribe una obra en la que "se vuelve" al tema de la llegada de los españoles a territorio americano, en este caso, a la expedición emprendida por Orellana hacia 1541 en busca de canela. Ese tema recurrente, en términos generales, en la literatura latinoamericana nos lleva a preguntas en varias direcciones, la más inmediata en el campo de los estudios literarios, sería si con esta novela hay una continuidad en la forma de tratamiento de aquel período histórico y de ser así, si la obra se puede enmarcar en la tendencia con la que se cierra el siglo XX en América Latina o si, por el contrario, se está abriendo paso a una nueva propuesta.
\end{abstract}

Palabras clave: El país de la canela; William Ospina; Novela colombiana.

\begin{abstract}
El país de la canela (2008),by William Ospina (1954) deserves attention, among others, and the subject matter that is at first sight. Moving away from the current issue of their Colombian contemporary narrative, in the XXI century, Ospina wrote a work in which "becomes" the subject of the arrival of the Spanish in American territory, in this case, the expedition undertaken by Orellana around 1541 in search of cinnamon. That appellant, in general terms, in Latin American literature topic brings up questions in several directions, the most immediate in the field of literary studies, this novel would be if there is a continuity in the form of treatment that historical period and otherwise, if the work can be framed in the trend with which the twentieth century closes in Latin America or, on the contrary, is making way for a new proposal.
\end{abstract}

Keywords: El país de la canela; William Ospina; Colombian novel.

Teniendo en cuenta que una de las características generales de la narrativa latinoamericana con la cual termina el siglo pasado es su fuerte tendencia hacia la novela histórica, y que $\mathrm{El}$ país de la canela ya desde el título y el tema se ubicaría en torno a esa tendencia, la ruta de investigación invita con insistencia a apoyarnos en las teorías existentes hasta hoy sobre novela histórica. Y, si a esto se suma el hecho de que la materia histórica dentro de la 
literatura tiende hacia un tipo de interpretación, es un sesgo, digamos con Noé Jitrik, ideológico $^{13}$, la pregunta que nos orienta, también con insistencia, es: ¿qué nueva o vieja orientación quiere dar Ospina al tema?, ¿para qué revivir un momento tan preciso como el de la expedición de Orellana por el Amazonas, ahora?

Con la clara intención de seguir las pistas que nos deja a primera vista el autor, nos remitimos a la documentación teórica sobre novela histórica y a los trabajos académicos que ya se han ocupado de ese tema en El país de la canela pero pronto notamos que la novela tropieza con la teoría y se siembra la duda de si las características de la novela histórica, particularmente las de la llamada Nueva Novela, se pueden contratastar en la obra sin forzarla demasiado. El asunto del género al que pertenece adquiere en ese caso una nueva dimensión. Si bien la clasificación no tiene demasiadas implicaciones en la valoración o el peso narrativo de una obra, la mayoría de veces, de las posiblidades que surgen al poner en duda su pertenencia a ese género específico, sale la hipótesis de este ensayo. Creemos que, a pesar de las evidencias, que casi empujan al lector hacia lo histórico, al final, el autor no logra hacer girar su relato en torno a ese discurso. Ospina le quita a la historia los personajes y los sucesos de la expedición de 1541 y los pone a girar en torno a otro universo que encontramos muy cercano al de los orígenes del romanticismo en el siglo XIX. La apuesta de Ospina en el País de la canela es, como creemos poder demostrarlo, escribir en el siglo XXI "la novela romántica" como no se produjo en el XIX, ni tampoco después, en Colombia.

\section{LA NOVELA HISTÓRICA}

\section{La Nueva Novela Historia de América latina (NNHAL)}

Los estudios sobre novela histórica latinoamericana en general giran en torno a dos ejes que se identifican sin mucha dificultad: de un lado, los que se apoyan en la teoría de la Novela Histórica Clásica (NHC), cuyo punto central de referencia es la obra de George Lukacs, así titulada, que describe el surgimiento de este tipo de novela en el siglo XIX; y, del otro, los que lo hacen en la llamada Nueva Novela Histórica de América Latina (NNHAL), concepto

\footnotetext{
13 "Entendiendo por ideología justamente la primera representación que nos hacemos de las cosas para poder dominarlas desde la perspectiva de nuestro interés o nuestra seguridad" Noé JITRIK. Historia e Imaginación literaria. Editorial Biblos, Argentina, 1995. Pg 56
} 
de Fernando Aínsa que hace referencia a una nueva tendencia narrativa en la región a finales del siglo XX, opuesta a la NHC.

La explicación de Aínsa en su libro Reescribir el pasado ${ }^{14}$ sobre las carácterísticas de la novela histórica después de los años 70 en América Latina, sin ser la única pero que ha servido como base para otras investigaciones en ese campo, ayuda a entender la obra de autores recientes que se ocupan, a través de la ficción, de temas históricos ${ }^{15}$. Para su surgimiento se señalan varias fechas y sucesos como puntos de referencia pero todos los estudios coinciden en señalar que ya algunas novelas habían anticipado el auge de esta tendencia que llega a su punto más alto en los 80. Retomando las palabras puntuales de Seymour Menton al referirse a la génesis de la NNHAL, resumimos: "Sea 1949, 1974, 1975 o $1979^{16}$ el año oficial de la Nueva Novela Histórica, no cabe duda que fue engendrada por Carpentier con apoyo de Borges, Fuentes y Roa Bastos” (MENTON, 1993:45)

Al decir de este autor entonces, no estamos tanto ante un cambio marcado por una situación social o política determinada, como si sucede con la NHC, como se verá adelante, sino que su surgimiento estaría más estrechamente ligado a la publicación de algunas novelas que, a pesar de sus marcadas diferencias entre sí, en conjunto, terminan perfilando una forma diferente de entender la Historia, se lee ahora la clara intención de los novelistas de desmarcarse de las llamadas historias oficiales. El foco cambia de objetivo y apunta hacia lo particular, la parte más humana o contradictoria, la cara más ridícula o burlesca de un personaje o suceso histórico reputado, o no. La interpretación y re-creación de los sucesos o de los personajes se vuelve central y la Historia, como tal, se convierte en un instrumento más para el novelista.

Pero, según Aínsa hay un elemento que abandera ese proceso de cambio y es el descontento y la posición crítica de los narradores hacia la Historia en general. Las motivaciones de los

\footnotetext{
${ }^{14}$ Fernando AÍNSA. Reescribir el pasado. Historia y ficción en América Latina. CELARG. El otro, el mismo. Mérida Venezuela, 2003.

${ }^{15}$ Remitimos al lector al interesante trabajo que hace Antonia Viu sobre las diferentes formas de acercamiento que hay hasta hoy a nivel teórico sobre la actual narrativa hispanoamericana y una valiosa concatenación de teorías que rescata las diferencias entre unas y otras. Antonia VIU. "Una poética para el encuentro entre historia y ficción" En: Revista Chilena de Literatura.Departamento de Literatura. Facultad de Filosofía y Humanidades. Universidad de Chile. Abril 2007, Número 70. pp.167-178.

${ }^{16}$ El reino de este mundo (1949), Carpentier,; Yo, el supremo (1974), Roa Bastos; Terra Nostra (1975), Fuentes, El mar de Lentejas (1979), Benítez Rojo. Menton nos recuerda además que, "el número de novelas históricas en general publicadas en los últimos 13 años, 1979-1992 excede al número de novelas publicadas en los 29 años anteriores 19491978. Seymour MENTON. La Nueva Novela Histórica de América Latina, 1979-1992. Fondo de Cultura Económica. México, 1993, p. 45.
} 
autores son variadas y en ellas sin duda interviene la situación social y política de cada país y del continente, pero lo cierto es que surge, dice: "una perspectiva desencantada del tiempo" (AÍNSA, 2003:75). Este autor define la NNHAL destacando no tanto las estrategias narrativas, en las que coincide con Menton y otros, sino que señala como punto central del cambio la perpectiva con la que los autores entienden y asumen en la narrativa, la Historia. La documentación ya no es fuente de información o soporte de veracidad, sino de crítica. Dice Aínsa: "La nueva novela histórica al propiciar un acercamiento al pasado en actitud noveladora y dialogante, elimina la "distancia épica" de la novela histórica tradicional y propicia una revisión crítica de los mitos constitutivos de la nacionalidad" (29). Las características que menciona Aínsa están sujetas a una clara intención de impugnar las verdades históricas sobre las que se ha construído cada una de las naciones latinoamericanas.

$\mathrm{Si}$ ante este panorama muy general de la tendencia que marcó la literatura de finales del siglo XX en América Latina, tratamos de ubicar nuestra novela, encontramos que El país de la canela -a pesar de los estudios que se han consagrado al tema ${ }^{17}$ - desajusta en lo esencial: la visión crítica del autor. Si bien hay algunos rasgos formales que se pueden encontrar en el estilo narrativo de Ospina como la intertextualidad, el relato en primera persona, la ficcionalización de personajes históricos o el no privilegiar las fechas o los sucesos ante lo ficcionalizado, el objetivo que persiguen estos rasgos formales está en una perspectiva temporal de la historia más cercana a la de la NHC que a la de la NNHAL.

\section{La Novela Histórica Clásica (NHC)}

Ospina en muy pocos momentos de su narración se aleja del relato "oficial". No nos cuenta en lo sustancial nada diferente de lo ya contado por Fray Gaspar de Carvajal en su crónica del viaje de Orellana por el Amazonas o del mismo relato que hace del tema Gonzalo Fernández de Oviedo. El título- programa que se solía dar a las crónicas del siglo XVI y que da a su obra el fraile sobre esa misma travesía por el Amazonas, bien podría resumir el tema general que trata en su obra Ospina: "Relación del nuevo descubrimiento del famoso rio Grande que descubrió por muy gran ventura el Capitán Francisco de Orellana desde su nacimiento hasta salir al mar con cincuenta y siete hombres que trajo consigo y se echó a su ventura por el dicho rio, y por el nombre del Capitán que le descubrió le llamó el Rio de

\footnotetext{
${ }^{17}$ Libardo VARGAS CELEMIN. "El país de la canela: Historia y ficción”. En Espéculo: Revista de estudios literarios. Universidad Complutense de Madrid, 2009.
} 
Orellana". Tema que tampoco se desprende de lo contado por Gonzalo Fernández de Oviedo en su Historia general y natural de las Indias escrita en 1542, y que ya retomaba en su Relación, Fray Gaspar de Carvajal.

Ospina en boca de su narrador agrega detalles y datos que recrean la travesía pero sobre un plano de la historia firmemente aferrado a los cánones clásicos de la novela histórica. Entonces, ¿qué cuenta el autor que ya no sepa la historia? El título-programa que se mencionó arriba nos sirve para ejemplificar el grado de "novedad", en cuanto a lo puramente informativo, que adiciona nuestro autor:

"Orellana siempre afirmó que había embarcado cincuenta y siete hombres: Pero Fray Gaspar de Carvajal declaró en sus memorias haber contado cincuenta y seis en el momento de partir y haberlo anotado así en sus papeles de viaje, para descubrir más tarde que éramos en realidad cincuenta y siete. A mí me ocurrió lo mismo, y después me dije que quizá los que contábamos no nos incluimos en la cuenta, pero es extraño que nos haya ocurrido a los dos. Y debo confesar que ni él ni yo incluimos en la cuenta a los esclavos negros ni a los indios" (OSPINA 2008:159).

Este "yo" que confiesa su error de cálculo es el mismo que a lo largo del relato va a validar todas las instancias y el mismo que inclina la narración hacia los inicios de la novela histórica clásica y hacia la concepción romántica del mundo que le da origen.

Un repaso al estudio de Lukacs nos ayuda a ver mejor la proximidad de El país de la canela a este género de la NHC por la forma en que se concibe lo histórico. Esta obra de Lukacs sigue siendo obligada referencia, entre otras muchas cosas, por sustentar la génesis de la novela histórica a partir del momento específico que vive la Europa del siglo XIX. Lukacs, señala la forma como el germen de la Revolución Francesa y las campañas napoleónicas fueron creando en la población el rechazo al absolutismo y a su vez, o como consecuencia, aparece un exacerbado sentimiento nacionalista - alimentado ya por el romanticismo- y una vivencia de las historias nacionales en todas las capas sociales que se van a reflejar en la literatura, particularmente en la narrativa. La obra de Walter Scott, el mejor ejemplo.

El proceso histórico escocés que describe Scott en sus novelas, dice Lukacs, es visto como un desarrollo propio de la evolución de su sociedad. La distancia con la que Scott lee la historia nacional sirve, no tanto para interpretar el pasado o el mismo presente como para afirmar la idea de que esta, la historia, es el resultado de una evolución lenta, constante y 
homogénea de acontecimientos que en conjunto la conforman. "Mediante un estudio histórico de la evolución inglesa total -Scott- trata de encontrar un camino medio entre ambos extremos combatientes" (LUKACS,18). Sin tomar posición en las disputas políticas o sociales de la época que trata en sus novelas, presenta una perspectiva de la historia nacional ligada a los personajes que crea. "Lo importante es provocar la vivencia de los móviles sociales e individuales por los que los hombres pensaron, sintieron y actuaron del modo en que ocurrió en la realidad histórica (...) De lo que se trata en la novela histórica es de demostrar con medios poéticos la existencia, el ser así de las circunstancias históricas y sus personajes" (27).

El gran logro de Scott fue entonces hacer manifiesta en la creación de sus personajes la vivencia de lo histórico, ese sentimiento nacional que se vive en todas las capas sociales y, dando existencia a quienes sin haber sido héroes también formaron parte del desarrollo histórico escocés, apuesta por una suerte de "democratización” de la historia a través de su narrativa. Así rompe con la tendencia del relato épico, común en su tiempo. "Su grandeza es la vivificación humana de tipos histórico-sociales(...) La figura central de Scott es siempre el héroe mediocre y prosáico" (19).

Sin dar continuidad al desarrollo evolutivo-cronológico de la novela en Colombia ni tampoco en América Latina, William Ospina en El país de la canela se acerca a la idea de historia que sostiene a la Novela Histórica Clásica, en la medida en que la distancia temporal que separa al autor de los hechos narrados, cinco siglos, no lo pone ante ellos en actitud crítica sino que su lectura del pasado, se aleja de los juicios de valor y parece proponerse más bien ubicar a sus personajes como hijos de su tiempo. "Para entender a esos hombres de Extremadura (a los hermanos Pizarro), que fundidos a sus potros enormes fueron capaces de dar muerte a un dios, tenemos que pensar en la dureza de la vida de España cuando no se ha nacido en cuna de príncipes" (OSPINA, 2008: 90), dice.

La perspectiva temporal queda arropada toda bajo el "no pudo ser de otra forma". Las atrocidades, o no, de la conquista y la colonia fueron en proporción a la época en que sucedieron y de ahí que podamos decir con Lukacs, al referirse a Scott, que Ospina, “(...) trata de encontrar un camino medio entre ambos extremos combatientes".

La condición mestiza de quien narra la travesía por el Amazonas en El país de la canela (hijo de indígena y español) le hace constantemente estar en medio de las dos posiciones 
que leemos hoy sobre la época, sin que tome partido por alguna. El narrador de la novela al contar cómo Pizarro en un ataque de ira y cansancio físico decide, sin dudar, "echar" a los indios a los perros, concluye diciendo: "Muchos hechos crueles se ven legitimados en estas tierras por la presión de las circunstancias, por el deber imperioso de sobrevivir a como dé lugar" (133). El narrador permanetemente se mueve entre la admiración por la campaña de los conquistadores - por su padre- o la grandeza del pueblo inca en su resistencia -por su madre- y el abatimiento por las penalidades de uno y otro bando. Los dos polos que se oponen están presentes casi en igual medida a lo largo de la novela.

Sin embargo, Ospina no logra el equilibrio que argumenta Lukacs para el caso de la novela histórica clásica. Según la lectura de Lukacs sobre la obra de Scott, esta solo pudo ser producto de alguien con una profunda conciencia de la "prosaización del mundo"; y, es ahí justamente donde Ospina se aleja de ese género. Aunque logra "desnudar" al heroe, y sus personajes en la novela se nos revelan en su dimensión más humana, son ciertamente héroes mediocres, como los llama Lukacs al referirse a los que elabora Scott; al final para Ospina y su narrador, aunque son conscientes de esa prosaización, no hay conformidad. Aunque los sucesos demuestren y determinen la evolución de la historia y esta vaya aferrada a la inminencia de un destino trazado y claramente fatídico, al final, sus personajes se resisten. Desde antes de emprender el viaje por la cordillera tanto el narrador, como Pizarro y el mismo Orellana, quien ya había hecho esa ruta, sabían que no existían las tierras de la canela. Antes de internarse en la selva, y cuando preparan los aperos en Quito para la partida a la expedición los nativos advierten al narrador: “(...) cuando le pregunté a uno de esos hombres de cobre(...) que tan lejos estaba de Quito el país de los caneleros, para mi asombro me contestó que no había tal cosa, que en estas tierras los árboles son todos distintos y que él no había oído jamás de un bosque donde todos los árboles fueran iguales. "Si eso es lo que esperan encontrar, se nota que no saben nada de la tierra. Estas terrazas no son montañas de cultivo“, añadió.” (84)

Pero, aún así, todos parten hacia la gran expedición. El viaje por el Amazonas es la metáfora de la inminencia del destino. Pero a la vez es la metáfora que puede actualizar para el lector del siglo XXI el tema de la novela, según su autor, como veremos. "Todos creyeron, todos creímos a ciegas en el País de la Canela, porque alguien había contado que ese país existía y centenares de hombres necesitábamos que existiera" 


\section{El universo romántico}

Por el tema que aquí interesa nos vamos a referir, no a la forma como entró el romanticismo en América a principios del siglo XIX, sino a los inicios de lo que fue el movimiento porque en ellos Ospina sostiene la armadura de su novela. La perspectiva del romaticismo como lo lee Ospina es una lectura más bien contemporánea de este movimiento, pues al remontarse a sus orígenes deja ver el filtro hecho por el tiempo y los críticos de tantas latitudes sobre lo que significó y puede significar en el presente.

Las palabras de Isaiah Berlin, uno de los más importantes teóricos del romanticismo, puede ayudarnos a introducir las ideas de Ospina. En su libro Las raíces del romanticismo ${ }^{18}$ sostiene que el proceso de cambio que se da con el romanticismo sin ser del todo uniforme empieza atacando las ideas y los valores que sostenían la sociedad europea de finales del siglo XVIII. Por el camino de la razón, sostenían los ilustrados, el hombre podía encontrar su lugar en el mundo y la armonía necesaria para sostener el equilibrio. Si bien la Revolución Francesa tuvo un importante influjo en lo que fue la actitud de los intelectuales ante la racionalidad, para Berlin mucho más influyente fue el pietismo en Alemania: "una rama del luteranismo que consistía en el estudio de la biblia y en el respeto profundo de Dios. (...) El resultado fue una intensa vida interior, una gran cantidad de literatura muy conmovedora e interesante aunque altamente personal y violentamente emocional y un rechazo por lo intelectual" (BERLIN, 2000:63). "Sturm und drang", "tormenta e ímpetu". Esa vida interior y esa religiosidad son las que van a prolongar su influencia. Para Berlin es clave la figura de Johann Georg Hamann, a su juicio fue el mayor de los románticos,. Él, dice Berlin, "fue el primero en declararle la guerra a la Ilustración del modo más abierto, violento y completo" (73), y quien puso los pilares definitivos del movimiento romántico. Según Hamann: "Si Dios no era un geómetra o un matemático sino un poeta, había algo de blasfemo en intentar adjudicarle a Dios subrepticiamente nuestros propios e insignificantes esquemas lógicos humanos" (75). Y más adelante destaca como, "fue uno de los primeros en señalar que los mitos no eran simplemente narraciones falsas sobre el mundo(...) Los mitos eran el modo en que los seres humanos expresaban su sentido de lo inefable, los

\footnotetext{
${ }^{18}$ Isaiah BERLIN. Las raíces del romanticismo.Taurus; España, 2000.
} 
misterios inexpresables de la naturaleza, y no había ningún otro modo en que pudiera expresarse" (76).

Así llegamos al legado más sólido y reconocido hoy del romanticismo: su férrea defensa de la voluntad del hombre y la exaltación de sus sentimientos ante el cálculo que impone la racionalidad e incluso ante las ataduras de la misma historia. "Cada época tiene su propio ideal y, por tanto, cualquier retorno nostálgico al pasado, es un sinsentido"(95) ${ }^{19}$. Un mecanismo de resistencia.

La naturaleza se convierte en la mejor aliada del hombre porque de ella puede reaprender el camino de retorno al orígen. Y de ese anhelo de retorno nace la nueva literatura. Más que rasgos característicos, como se suelen describir los movimientos literarios, es la fuerza de la voluntad sobre la razón lo se impone con el romanticismo, y a ella parece aferrarse Ospina. En sus ensayos recopilados en el libro Es tarde para el hombre, el autor en forma clara, manifiesta su "nostalgia" por los mejores tiempos idos ${ }^{20}$. Ante el avance del capital y las avasalladoras tecnologías, lo que cabe es acusar la pérdida de lo divino, la dimensión de lo sagrado, lo misterioso. Y es en este punto en que aparece para Ospina el Romanticismo como un desafío no sólo a la razón sino a la homogenización de valores en torno a la economía; frente a un capitalismo desmedido que ha convertido en mercancía al hombre y también a la naturaleza. Reto que, seguimos con Ospina, si llegó a desafiar al positivismo en sus días puede llegar a desafiar también al capitalismo en pro del hombre y su humanidad. O volvemos a la arcadia pasional, al furor romántico o nos volcamos al mundo del cálculo racional de la economías del mercado global.

Ospina hace una lectura del romanticismo actualizando su legado en actitud bastante cercana a la que nos muestra Berlin en su ensayo sobre los orígenes de este movimiento. Según los críticos de Ospina uno de sus principales defectos es precisamente ese, su insistencia en querer revivir constantemente el "mito de que todo pasado fue mejor" ${ }^{21}$. Y, sin duda, tanto en sus ensayos como en sus poemas, Ospina muestra una obstinada preocupación por lo "perdido": los valores, los sueños, los mitos, lo divino, el misterio, el hombre mismo. Ideas esquematizadas y lugares comunes que en los ensayos agotan al lector pero en El país de la canela adquieren una dimensión diferente gracias los alcances

\footnotetext{
${ }^{19}$ Isaiah BERLIN. Las raíces del romanticismo.Taurus; España, 2000. Retoma en esta cita las palabras de Herder.

${ }^{20}$ William OSPINA. "Los románticos y el futuro". En: Es tarde para el hombre. Editorial Norma. Pp.13-35.

${ }^{21}$ Andrés HOYOS.’Es tarde para la ingenuidad”. En: Boletín Cultural y Bibliográfico B.L.A.A, Número 38. Volúmen XXXII, Colombia, 1995.
} 
de la voz narradora. Valga un ejemplo. Luego de contar los enormes esfuerzos de Pizarro en busca del tesoro de Pachacamac que al final solo lo llevan a "un antro detestable", descubre que Pachacamac es la divinidad hecha de los penosos pasos que lo llevaron a ella. "Uno cree saber lo que busca, pero sólo al final, cuando lo encuentra, comprende realmente qué andaba buscando. Y bien podría ser que lo que rige el destino del hombre no sea Cristo ni Júpiter ni Alá ni Moloch sino Pachacamac, el dios de los avances hacia ninguna parte, el dios de la sabiduría que llega un días después del fracaso" (OSPINA, 2008:351). Y volvemos aquí a detenernos en el narrador.

\section{El narrador romántico}

La particularidad que tiene la identidad de la voz narradora, es el eje central de la novela. $E l$ país de la canela es el relato en primera persona de un mestizo que recuerda, en 1557, su niñez y la expedición en la que participa a sus 20 años en busca de los bosques de canela. Y, llama la atención no solo por su condición racial-una voz no reputada por la historia que cuenta- sino en principio por los detalles con los que da vivacidad a lo contado y por el trato que da a las fuentes de información histórica.

A pesar de que las evidencias documentales constantes a lo largo de la novela coinciden con lo registrado por la historia oficial: la caída del imperio inca, las disputas por las tierras conquistadas y sus tesoros, las fechas de la expedición por el Amazonas, los nombres de quienes participaron, la ruta misma de la travesía, etc., desde las primeras líneas y hasta el final, constamente el lector va a poner en duda la fidelidad de lo contado. Estamos ante un narrador que a pesar de la documentación escrita que tiene en sus manos, y que "muestra" al lector, apela a su memoria como principal fuente de información. "La primera ciudad que recuerdo vino a mí por los mares en un barco. Era la descripción que nos hizo mi padre en su carta de la capital del imperio de los incas. Yo tenía doce años cuando Amaney, mi nodriza india, me entregó aquella carta, y en ella el trazado de una ciudad de leyenda que mi imaginación enriqueció de detalles.” (15).

Pero, sin pretender una memoria prodigiosa, constantemente nos va a recordar que esa fuente solo puede ser frágil y voluble. "No sé si esa lectura (de la carta del padre) fue entonces la prueba de las ciudades que había sido capaz de construir una raza: al menos fue la prueba de las ciudades que es capaz de imaginar un niño" (16) El relato entonces está 
tejido, de principio a fin, por la memoria del narrador; y, llegamos a pensar incluso, porque el narrador así nos lo hace creer, que no es seguro si la expedición misma ha sido real o si ha sido producto de su imaginación. "Cada quien vivió su propia experiencia de la selva, y cada quien contará una historia distinta, pero puedo decirte que al final de ese viaje hablamos de tantas cosas que ya no sé qué vimos" (45)

Todo lo que hasta entonces había sido instrumento para validar aquel momento histórico, la documentación, las fechas y los nombres, aquí también queda registrado pero sujeto a la subjetividad del narrador. Su permanente dudar conforma una intimidad que es al fin la que registra y valida hechos y personajes. En la esfera de lo personal se juega su papel la Historia. Al poder de la elaboración de un relato a través de los meandros inciertos que recorre la memoria se supeditan todas las instancias. No son los hechos lo que importa ni tampoco la precisión.

Luego de todas las penurias del recorrido el narrador cuenta a su maestro Oviedo la travesía por el Amazonas y éste escribe una carta para enterar a su amigo Pietro Bembo y otras altas jerarquías del viejo continente sobre el nuevo territorio descubierto. El narrador parte a Europa, "no llevaba -dice- al Viejo Mundo sólo la memoria de mis aventuras sino una crónica escrita por el mayor testigo de aquel tiempo" (297).

Gonzalo Fernández de Oviedo, sin haber participado directamente de la expedición es el mejor testigo de lo ocurrido porque materializa la memoria en la escritura, incluso para el narrador que ha padecido la larga travesía. No está en juego la veracidad, está en juego el poder de la palabra y la credibilidad del relato.

Cuando llega a Europa a mostrar la carta de Oviedo y contar lo que ha visto se encuentra con que las autoridades que se reúnen para recibirlo solo quieren oír hablar de las Amazonas, el viejo mito que ahora cobraba vida al otro lado del Atlántico.

"Toda esa gente estaba concentrada en lo suyo, tan convencida de que su mundo era todo el mundo, que pronto comprendí que las Indias no cabían en la vida cotidiana de aquellos reinos, y yo mismo era un poco invisible” (298)

"Nunca vi gente menos interesada en enterarse de lo que pasaba en el mundo ni más indiferente a los hechos cuando éstos no coincidían con sus ideas. Ahora cada uno sabía más que el otro, y parecían más decididos a aclarar sus propias ideas y costumbres que a pensar en el descubrimiento. Durante muchos días no se habló de otra cosa. Las amazonas 
eran el tema, pero eran sobre todo el pretexto para que los cardenales ostentaran su erudición."(314).

Así entonces ni el relato ni tampoco el texto tienen credibilidad. El narrador está solo con su recuerdo y sus inciertas vivencias. Su único interlocutor, muchos años más tarde, es Pedro de Ursúa. Y, a él decide revivirle la travesía porque pretende emprender esa ruta y hacerlo desistir de tal despropósito lo obliga a revivir sus recuerdos."Solo se puede ir a esas tierras como fuimos nosotros: por azar y por accidente, y no está en sus cabales el que emprenda el camino sabiendo qué le espera. Por eso me importa contártelo todo con el mayor detalle" (106).

Pero contra todo pronóstico de lo racional y de lo histórico al final, no sin advertirle por una última vez que es posible que no vuelvan con vida y que mil veces no lo acompañará, y cuando "Todo me está gritando que te detenga... (...) ya temo que no seré capaz de dejarte correr solo ese riesgo, y entonces iré contigo, Pedro de Ursúa, aunque sé lo que nos espera, y me volveré tu sombra, aunque será lo último que nos dejen hacer en el mundo.” (360).

La serpiente mordiéndose la cola, esa es la historia Un devenir circular, una cadena de repeticiones que todo lo hace previsible. Toda racionalidad repite, el narrador lo sabe y, por eso se juega su última carta a lo incierto, se la juega de nuevo al azar de la aventura. Y nace para el lector Ursúa, (2005), la primera novela de la trilogía de La serpiente sin ojos en donde Pedro de Ursúa se encuentra con todas las marravillas y penalidades de que le aguardan en el "Nuevo" Mundo.

\section{Conclusión}

Ospina no se ubica en el presente del lector, su distancia, de los sucesos narrados y la del narrador están más en el imaginario del siglo XIX que en el del XX o el XXI. La actualización del mito romántico es el indicio más cercano al presente del lector. La idea de Historia de Ospina no está condicionada al documento sino se aferra a los relatos que pueda organizar la memoria.. Ospina no "impugna", no "cuestiona" y tampoco "re-interpreta" verdades. Saca el tema del ámbito de la historia y lo ubica en los orígenes del romanticismo como una manera de universalizar o más bien "democratizar" un heroismo ya no de caracter épico por imposible, sino más bien romántico. El deseo de creer y la necesidad de hacerlo como único sustento de humanidad que puede albergar el hombre. La vida del mito 
no como retorno ingenuo o evasivo de realidad sino como una necesidad vital de la humanidad para sostenerse.

\section{Referencias}

-Fernando AÍNSA (2003) Reescribir el pasado. CELARG. El otro, el mismo. Mérida, Venezuela.

-Isaiah BERLIN (2000), Las raíces del romanticismo. Taurus, Madrid.

-Emilio CARILLA (1975), El romanticismo en la América Hispánica. Tomo I. Editorial Gredos. Madrid.

-Andrés HOYOS (1995), "Es tarde para la ingenuidad". En: Boletín Cultural y Bibliográfico B.L.A.A, Número 38. Volúmen XXXII, Colombia.

-Noé JITRIK Historia e imaginación literaria (1995), Editorial Biblos. Argentina.

-Seymour MENTON (1993), La nueva novela histórica de América Latina, 1979-1992.

Fondo de Cultura Económica. México.

-William OSPINA (2008), El país de la canela. Grupo editorial Norma Colombia. (2006) Es tarde para el hombre. Grupo editorial Norma Colombia. (2005), Ursúa. Alfaguara. Colombia.

-Henri PEYRE (1972), El romanticismo. ¿Qué es verdaderamente?. Doncel. Madrid. -Georg LUKACS (2003-2007), La forma clásica de la novela histórica. Archivo Chile Historia político social. En Internet: http://www.archivochile.com/Ideas-Autores/Lukacs -Libardo VARGAS CELEMÍN (2009), “El país de la canela: Historia y ficción”. En: Espéculo Revista de estudios Literarios. Universidad Complutense de madrid. España. -Antonia VIU (2007), “Una poética para el encuentro de historia y ficción”. En: Revista chilena de literatura. Abril, Número 70, 167-178. 